\section{NEONATE WITH MIXED GONADAL DYSGENESIS: CHALLENGES IN SEX ASSIGNMENT}

Shi Yun Chia, Rashida Farhad Vasanwala. Singapore

\subsection{6/bmjpo-2021-RCPCH.225}

Background 45,X/46,XY mixed gonadal dysgenesis (MGD) is a disorder of sex development characterized by a broad phenotypic spectrum. Patients may have unilateral, bilateral or no testis, streak gonads and/or persistent Mullerian structures. It poses a great clinical challenge due to known effects on growth, hormonal balance and gonadal development.

Objectives We present a case of $45, \mathrm{X} / 46, \mathrm{XY}$ mixed gonadal dysgenesis (MGD) and the challenges of gender assignment discussion with the patient's family

\section{Methods Clinical Case Report}

A term new-born infant, delivered at home, presented to the neonatal unit with ambiguous genitalia. Examination revealed a $1.5 \mathrm{~cm}$ midline phallic structure, with labial-scrotal folds with rugosity but no urethral opening (figure 1), two external openings at introitus (urethral and vaginal) (figures 2 and 3), and bilateral palpable inguinal gonads, right larger than left.

Results Ultrasound of the pelvis showed a uterus, cervix and vagina with possible right intra-abdominal testis. The neonate passed a synacthen test and had normal 17-Alpha-Hydroxyprogesterone. Gonadotropins (Follicle stimulating hormone and Luteinizing hormone), testosterone and Anti-mullerian hormone were normal but there was no detectable oestradiol. Cytogenetic investigation included FISH and karyotype which showed 45,X[22]/46,X,idic $(\mathrm{Y})(\mathrm{q} 11)[8]$. ish $\quad \operatorname{idic}(\mathrm{Y})(\mathrm{p} 11.3)$ (SRYx2), of which $25 \%$ of cells were Y-containing, while $75 \%$ were X-containing. Exploratory laparoscopy with biopsy of bilateral gonads showed right gonadal tissue (figure. 4) and left hemi-uterus and fallopian tube with no ovary (figure. 5). Histology confirmed right testicular tissue and left sided structure resembling fallopian tube showed no ovarian stroma, primordial follicles, nor seminiferous tubules. Findings and options regarding sex of rearing, surgical and medical treatment, were discussed in the family conference. The structure of discussion is appended in table 1 .

Conclusions The management of MGD is multi-disciplinary. Gender assignment is based on the consideration of several factors, including external and internal genital findings, the role of surgical procedures required, future prospects of hormone replacement, fertility, urinary \& sexual function and risk of gonadal malignancy. In addition, social and psychological support is important as the family makes the decision on gender assignment.

\section{STUDY ON RETINOPATHY OF PREMATURITY - INCIDENCE, RISK FACTORS \& OUTCOME}

Ankita Halder, Asha Mukherjee, PK Saraf. India

\subsection{6/bmjpo-2021-RCPCH.226}

Background Retinopathy of prematurity (ROP) is a potentially vision threatening disease affecting preterm babies. Progress in neonatal intensive care in recent years has led to an increased survival of preterm \& sick babies and subsequently, to an increasing incidence of ROP.

Objectives To analyze the incidence, risk factors and outcome of ROP.

\section{Methods}

STUDY POPULATION 50 Babies $\leq 32$ weeks gestational age and 50 preterm babies $>32$ weeks gestational age.

INCLUSION CRITERIA Babies with birth weight $\leq 1500$ g. Babies born at $\leq 32$ weeks of gestation. Selected preterm babies with a birth weight between 1500 grams and 2000 grams or gestational age of more than 32 weeks with additional risk factors (eg. oxygen therapy, sepsis, apnea, birth asphyxia, RDS, NEC, use of surfactant, exchange transfusion, IVH, PRBC transfusion).

Group1: Babies with gestation $\leq 32$ weeks and/or babies with birth weight $\leq 1500 \mathrm{~g}$.

Group2: Selected preterm babies with a birth weight between 1500 grams and 2000 grams or gestational age of more than 32 weeks with additional risk factors as mentioned above

EXCLUSION CRITERIA Outborn babies treated in our NICU STUDY PERIOD: 2017- 2018 When to screen: First screening examination should be carried out at 31 weeks of gestation or 4 weeks of age, whichever is later.

Abstract 406 Table 1 Structure of discussion with patient's family

\begin{tabular}{|c|c|c|c|c|c|c|}
\hline Sex of Rearing & Surgical Procedures Needed & $\begin{array}{l}\text { Future } \\
\text { Hormone } \\
\text { Therapy }\end{array}$ & Fertility & Sexual Function & $\begin{array}{l}\text { Urinary } \\
\text { Function }\end{array}$ & $\begin{array}{l}\text { Risk of } \\
\text { Cancer in } \\
\text { Testes }\end{array}$ \\
\hline Female & $\begin{array}{l}\text { vClitoral reduction } \\
\text { Removal of testes }\end{array}$ & $\begin{array}{l}\text { Estrogen } \\
\text { during } \\
\text { puberty }\end{array}$ & $\begin{array}{l}\text { vInfertile } \\
\text { Can conceive with egg donation } \\
\text { but with risk as uterus is abnormal }\end{array}$ & Intercourse possible & Intact & Nil \\
\hline Male & $\begin{array}{l}\text { vConstruction of penis, scrotal sac and urethra } \\
\text { Orchidopexy Removal of uterus and fallopian tubes }\end{array}$ & $\begin{array}{l}\text { May not need } \\
\text { testosterone }\end{array}$ & $\begin{array}{l}\text { vSub-fertile } \\
\text { Sperm banking may be possible }\end{array}$ & $\begin{array}{l}\text { Penile function affected } \\
\text { (erection during } \\
\text { intercourse) }\end{array}$ & $\begin{array}{l}\text { May need to } \\
\text { sit for } \\
\text { urination }\end{array}$ & $\begin{array}{l}\text { Approximately } \\
10 \%\end{array}$ \\
\hline $\begin{array}{l}\text { No assignment } \\
\text { currently; decision } \\
\text { later }\end{array}$ & $\begin{array}{l}\text { vTo decide at } 21 \text { years of age vReconstruction may } \\
\text { be more difficult at later age. } \\
\text { Genitalia may resemble male appearance as } \\
\text { testosterone is active up to } 1 \text { year. }\end{array}$ & $\begin{array}{l}\text { Depends on } \\
\text { chosen sex }\end{array}$ & $\begin{array}{l}\text { vSub-fertile as male } \\
\text { Infertile as female }\end{array}$ & Depends on chosen sex & $\begin{array}{l}\text { Sit for } \\
\text { urination } \\
\text { currently } \\
\text { Requires } \\
\text { reconstruction } \\
\text { later }\end{array}$ & $\begin{array}{l}\text { Approximately } \\
10 \%\end{array}$ \\
\hline
\end{tabular}


All the babies found to have ROP were regularly followed up in both our high risk clinic and in Ophthalmology outpatient department for one year.

Results Incidence of ROP was $23 \%$ in our study. Incidence was $38 \%$ in the 1 st group $\& 8 \%$ in the 2 nd group.

Most common findings were stage III ROP (39\%) and zone II ROP (70\%). 3 (13\%) had APROP (Aggressive posterior ROP) and 2 (8.7\%) had retinal detachment.

The incidence of ROP increased as the birth weight and period of gestation decreased- no ROP was found in gestation $\geq 35$ weeks and birth weight $>1.828 \mathrm{~kg}$.

In our study, oxygen administration through mechanical ventilator or CPAP, sepsis, therapy with surfactant, apnea, PRBC transfusion, NEC and birth asphyxia were found to be significant risk factors. The risk of ROP is more in RDS, IVH and only head box oxygenation but the risk is not significant. We have not found any ROP in the babies who have undergone exchange transfusion.

$13(57 \%)$ babies had spontaneous regression of ROP and rest $10(43 \%)$ required some intervention. To summarize the intervention $(\mathrm{n}=10), 5(50 \%)$ responded to LASER only, 3 $(30 \%)$ required intravitreal injection with Bevacizumab (antiVEGF) following LASER, 1 (10\%) required TPPV (Trans Pars Plana Vitrectomy) in left eye for ROP stage IVb along with LASER and 1 (10\%) baby required all the three- LASER, intravitreal Bevacizumab and left sided TPPV.

Conclusions Thus the need for a routine screening program for the detection of ROP in preterm and sick neonates with risk factors is very essential in our clinical settings. Prevention of blindness from ROP can be very effective through early detection and urgent treatment. This needs awareness among neonatologists and pediatricians for referral to the ophthalmologists at appropriate age of the baby.

\section{CAN WE REDUCE NEONATAL ADMISSIONS DUE TO JAUNDICE?}

Sonal Datir, Gopa Sarkar. UK

\subsection{6/bmjpo-2021-RCPCH.227}

Background Neonatal hyperbilirubinemia is a common cause for neonatal admission in term and preterm infants. These infants are primarily managed on postnatal wards; however, they require admission to neonatal unit due to jaundice above the exchange level, rapidly increasing bilirubin levels, pathological jaundice or sepsis.

Failure to initiate and establish adequate breastfeeding can play an important role in development of severe jaundice. Face-to-face professional support has been shown to increase breastfeeding success.

Objectives The objectives of this project included evaluation of the management of infants admitted to neonatal unit with jaundice including the feeding practices; and identifying the areas of improvement to reduce admissions.

Methods This was a retrospective observational project including infants born at $\geq 35$ weeks admitted to neonatal unit at District Hospital with a diagnosis of jaundice from January 1, 2017 to December 2018. Data was collected using proforma, medical records and blood results on computer system.

Results A total of 519 infants $\geq 35$ weeks were admitted to the neonatal unit of which $12 \%(60)$ infants were admitted due to jaundice. $42 \%(25)$ were preterm and $58 \%(35)$ were term infants.

The risk factors for jaundice were identified as male infant (66\%), first born (49\%), gestation, prematurity, and breast fed babies.

The mean birth weight was 2892.5 grams and 20\%(12) were low birth weight. 35\%(21) infants were admitted from home (average 3.9 days) and 65\%(39) from postnatal wards.

$27 \%(16)$ infants had jaundice $<24$ hours. 6 infants had $>$ $10 \%$ weight loss on admission. DAT was positive in $23 \%(14)$ infants of which 8 infants presented $<24$ hours.

Sepsis was suspected in $72 \%$ (43) infants but was proven in none.

Only 20\%(12) received lactation support on the postnatal ward prior to admission whereas $43 \%(26)$ did not receive any support. 36 infants were exclusively breastfed, 13 were formula fed and 11 were mixed-fed. After admission, formula feeds were added to 32 infants while 4 infants exclusively breast fed. 10 infants were given intravenous fluids.

The causes of jaundice included prematurity(25), ABO incompatibility(11), Rh incompatibility(3), poor feeding or exaggerated jaundice(25).

33 infants had bilirubin above exchange line, and required a mean of 24 hours (range 6- 144 hours) of phototherapy. None of them required immunoglobulins or exchange transfusion.

The mean length of stay was 3 days (range 1-14 days) and there was a remarkable decrease in breast feeding as only 7 (11.6\%) infants were breast fed on discharge.

Conclusions There is a scope to decrease the admissions due to jaundice by optimising the postnatal support on the postnatal wards and community in the presence of risk factors.

Transitional care for late preterm infants is important to reduce admission to the neonatal unit thereby reducing the separation of mother and baby.

The opportunities to support breast feeding on postnatal ward and neonatal unit are often missed.

Effective measures should be taken to promote lactation support at all levels.

\section{SYRINGE AIR FLUSH TECHNIQUE ELIMINATES SURFACTANT REFLUX AS A LIMITING FACTOR IN USING HIGHER VOLUME SURFACTANT FOR MINIMALLY INVASIVE SURFACTANT THERAPY}

Karthikeyan Gengaimuthu. United Arab Emirates

\subsection{6/bmjpo-2021-RCPCH.228}

Background Minimally Invasive Surfactant Therapy or Less Invasive Surfactant Administration (LISA) is the preferred way of administration of surfactant in neonates. Surfactant reflux resulting in ineffective surfactant delivery is considered a limiting factor in administering a higher volume surfactant like bovine surfactant by MIST.

Objectives To analyze if syringe air flush technique as incorporated in our MIST procedure protocol eliminates surfactant reflux with higher dose volume bovine surfactant in our cohort of babies that received surfactant by MIST.

Methods Syringe air flush after the surfactant administration is incorporated in our MIST procedure protocol, the default standard of administering surfactant in our neonatal units. Both porcine surfactant $(1.5 \mathrm{ml} / \mathrm{kg})$ and bovine surfactant 